\title{
Do Violent Video Games Impair The Effectiveness of In-Game Advertisements? The Impact of Gaming Environment on Brand Recall, Brand Attitude, and Purchase Intention
}

\author{
Seung-Chul Yoo, M.A., and Jorge Peña, Ph.D.
}

\begin{abstract}
The present study examined whether a violent video game impairs the effectiveness of in-game advertisements compared to a nonviolent video game. Participants recalled and evaluated in-game ads after navigating identical violent or nonviolent game scenarios. Participants' brand recall, recognition, and attitudes were comparatively lower after navigating the violent video game. Also, females in the violent game condition reported lower brand attitudes in comparison to males in the violent game condition, thus suggesting that the effects of gaming environment interacts with participants' gender. The findings supported the predictions of the limited capacity model of attention and cognitive priming effects. The results also extend previous studies on how violent media impair advertising effectiveness and provide practical implications for researchers and practitioners.
\end{abstract}

\section{Introduction}

A DVERTISERS BASE MOST OF THEIR MEDIA CAMPAIGN decisions on cost-efficiency calculations including a program's rating points. ${ }^{1}$ In this context, the most compelling reason why advertisers sponsor violent television programs is because they believe that these shows draw more viewers than nonviolent programs. ${ }^{2}$ Therefore, the proven popularity of violent television programs (e.g., 24) provides incentives to advertisers to embed their ads within violent programs or within subsequent commercial breaks in the hopes of raising brand and product exposure.

Following this tradition, advertisers have shown a strong interest in promoting their products, not only in television programs, but also in popular new media such as video games. ${ }^{3}$ A main reason for this is that in-game advertising bears the promise of reaching young and highly engaged consumers. ${ }^{3}$ For instance, virtually all American teens and almost half of all American adults play computer, console, or cell phone games, thus implying that a growing majority of Americans play some kind of video games. ${ }^{4,5}$ Almost half of all published video games are violent and, in particular, firstperson shooter games are a top-selling genre (e.g., Halo 3). ${ }^{6}$

Although advertisers assume that ad placement in violent media is a sound decision because of increased brand and product exposure, current empirical studies have instead demonstrated that, in fact, violent television programs are less effective than nonviolent programs in terms of advertising memorization effects. ${ }^{2,7,8}$ And while current studies have looked at the effectiveness of in-game advertising, ${ }^{3,9}$ researchers have not yet fully addressed whether violent video game environments (e.g., a first-person shooter like Doom 3) can impair in-game ad recall in comparison to nonviolent video game environments (e.g., a first-person exploration game like Myst) in ways similar to how violent television programs hamper ad recall relative to nonviolent television programs. ${ }^{7}$ For example, a recent study that used eyetracking technology failed to replicate ad impairment effects in the context of violent video games. ${ }^{10}$ While participants assigned to a violent game paid less visual attention to ingame ads compared to those assigned to a nonviolent game, the analysis did not uncover the predicted reduction of ingame ad effectiveness when playing violent games. ${ }^{10}$ Therefore, one contribution of the present research is revisiting the advertising impairment hypothesis in more depth.

More specifically, the present study compares the impact of video game context (violent vs. nonviolent) on advertising effectiveness. In particular, advertising effectiveness is related to increased ad recall, a more positive brand attitude, and a stronger purchase intention. ${ }^{11}$ Thus the present study investigates how situational cues in video game environments (i.e., presence or absence of violent cues) may affect in-game

Department of Advertising, The University of Texas at Austin, Austin, Texas. 
advertising effectiveness (i.e., ad recall and recognition, attitudes about the brand, and purchase intention) by drawing from the limited capacity model of attention and research on cognitive priming effects. Based on these models, we predict that violent video games may command more attention and limit awareness of in-game ads in comparison to nonviolent games. Violent video games may also elicit more negative thoughts and feelings for users than nonviolent video games. Overall, this is expected to diminish in-game ad effectiveness by reducing brand recall and recognition and by priming more negative brand attitudes and purchase intentions. Limited capacity and cognitive priming models are explained below, along with an experiment testing their predictions.

\section{The influence of violent media on brand recall}

Previous studies examining the effects of commercial messages suggest that prominent aspects of advertisements can activate specific product attributes in memory. ${ }^{12}$ For example, the context of print and television ads can influence individuals' mental states and subsequent cognitive processing of embedded advertising messages. ${ }^{13}$ In particular, violent television programs can significantly impair the memorization of advertisements. For example, one study found that participants were less likely to remember advertised brands when these were embedded in a violent television program in comparison to a neutral program. ${ }^{7}$

Why might exposure to violent media content reduce brand memorization? The limited capacity model of attention provides one explanation to this memory impairment effect. ${ }^{14,15}$ According to this model, violent media may impair ad effectiveness because they divert attention away from the advertisements. ${ }^{16}$ For example, current studies have demonstrated that individuals pay more attention to violent media than to nonviolent media. ${ }^{10,16}$ Also, violent media are more arousing than nonviolent media. This may take up more of the cognitive resources of the perceiver, thus inhibiting their recognition of new information. ${ }^{16}$ In sum, violent media not only draw perceivers' attention, but also divert attention from other sources of information.

These principles should also apply to first-person violent video games (e.g., Doom 3). These games are more violent, competitive, fast-paced, and emotionally arousing than nonviolent first-person video games (e.g., Myst). Violent video games may, therefore, induce strong cognitive and affective reactions from players, and the large amounts of cognitive resources spent on processing a hostile gaming environment are predicted to impair the effectiveness of in-game ads. Thus, all else being equal, the limited capacity model suggests that gamers may recall and recognize fewer in-game ads after playing a violent game. Hence:

H1: Participants that navigate a violent video game environment will recall and recognize fewer in-game ads compared to those that navigate an identical nonviolent video game environment.

In addition to our focus on the advertising impairment hypothesis, the present study is also interested in how gaming context affects the evaluation of in-game ads. In this regard, the following section reviews evidence suggesting that violent video games may not only diminish ad recall, but may also elicit more negative evaluations of in-game ads.

\section{The influence of environmental cues on brand attitudes and purchase intentions}

Can violent video games affect the evaluation of in-game ads (e.g., brand attitudes and purchase intentions)? Priming models examining how environmental cues and media content elicit thoughts, feelings, and behavioral schemas may provide one answer to this question. ${ }^{17}$ Priming mechanisms represent an unconscious human memory system connected to the perceptual identification of words and objects. ${ }^{18}$ Studies in this tradition indicate that salient environmental stimuli can alter the perception and interpretation of a secondary target stimulus. For example, participants exposed to concepts such as "reckless" and "adventurous" were more likely to use those concepts when making an impression on a stranger described ambiguously in a subsequent and seemingly unrelated task. ${ }^{19}$ This influence process is referred to as priming effects. ${ }^{18}$ In general, priming studies indicate that the interpretation of information depends on which concepts are most accessible in memory at the time that new information is processed. $^{17}$

Priming effects can also influence the processing of new advertisements. For instance, a recent study demonstrated that primed attributes were more likely to be utilized when processing new advertisements. ${ }^{20}$ For instance, brand evaluation was enhanced when the ad context presented positive attributes, yet was significantly diminished when the ad context raised negative implications. ${ }^{13,20}$ According to $\mathrm{Yi}^{13}$ priming effects in advertising operate below individuals' subjective awareness, since study participants remained unaware of the intended influence of ad context on their responses.

In the light of this research, we hypothesize that video games create a specific environment that makes certain attributes more salient. For example, violent video games tend to highlight negative concepts such as blood, hostility, firearms, and death. According to priming theorists, these environmental factors will elicit associations that will ultimately affect the interpretation of in-game advertisements. If cognitive priming theory applies to how people mentally process in-game ads then, all other things being equal, the negative associations made salient by a violent video game are expected to elicit more negative brand attitudes and lower purchase intentions in comparison to the effects of a nonviolent video game. Thus:

\begin{abstract}
H2: Participants that navigate a violent video game environment will have more negative brand attitudes and lower purchase intentions toward in-game ads compared to participants who navigate an identical nonviolent video game environment.
\end{abstract}

\section{Method}

\section{Overview}

The participants were randomly assigned to either a violent or a nonviolent video game. Their experimental task was to navigate the identical game environments from beginning to end. Both contexts featured the same embedded advertisements in similar fixed locations (see Figure 1). The environments were identical in every detail except for the presence or absence of violent cues. For example, the violent video game featured computer-operated avatars holding 

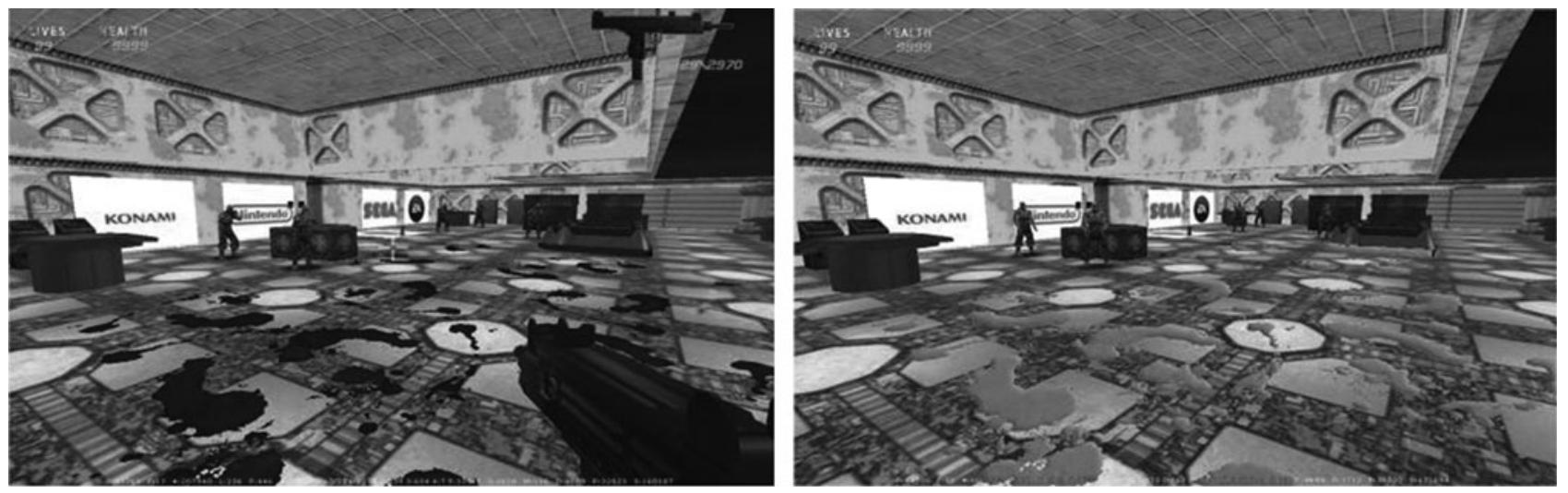

FIG. 1. Violent and nonviolent experimental video game conditions.

guns and shooting at the participant as he or she navigated through virtual rooms drenched in blood. In contrast, the nonviolent video game featured the same avatars holding nothing and the virtual rooms were soaked in water (see Figure 1). After the game navigation task was completed, each participant filled out brand recall, brand recognition, brand attitude, and purchase intention items, and then provided demographic information including how often they played video games.

Two manipulation checks were also included. The first check ensured that the participants perceived the content and graphics of the violent game as more aggressive than the nonviolent game. The second check addressed alternative explanations to limited capacity and priming models. For example, it is possible that playing violent video games increases participants' aggressive moods. ${ }^{21}$ If so, memory impairment effects could be tied to increases in aggressive affect, while the present study instead argues that the impairment effect is mostly connected to participants' cognitive processes. ${ }^{16,17}$ After completing the questionnaires the participants were fully debriefed and encouraged to ask questions about the study.

\section{Participants}

A total of 68 participants (34 males and 34 females) were recruited at a major southwestern university. Participants received a course credit in exchange for their participation. The cover story was the study of human interaction in virtual environments. The age of the participants in the sample ranged from 18 to $40(M=21.45, S D=2.62)$. A total of $86.8 \%$ of the participants were native English speakers, of which $41.2 \%$ were Caucasian, $26.5 \%$ were Latinos, $19.1 \%$ were Asian American or Pacific Islander, 10.3\% were of AfricanAmerican descent, and 2.9\% marked "other" as their racial heritage. Participants' video game experience varied from 0 to 18 years $(M=8.57, S D=5.64)$.

\section{Stimulus materials}

The most popular video game genre nowadays is the firstperson shooter game. ${ }^{6}$ Therefore, this genre was selected for the experimental stimuli. Game designer Ki-Hwan Lee professionally developed two identical video game environments for this experiment. The experimental video games were designed to resemble off-the-shelf first-person shooter games available in retail stores (Figure 1). The gaming environments consisted of three rooms. The first room was used as a training space to teach participants the basic controls, while the remaining rooms displayed the in-game ads. Large directional arrows were painted on the floor to prevent participants from getting lost in the virtual environment. A total of 10 computer-operated avatars were placed inside the video games. Five avatars were placed in the first room, while the rest were located in the final room. These avatars had the same robotic design in both conditions.

As indicated above, the stimuli video game has two versions (violent and nonviolent). The violent video game context was developed by following the operational definition of violence from the National Television Violence Study, ${ }^{22}$ that is "any overt depiction of a credible threat of physical force or he actual use of such force intended to physically harm an animate being or group of beings." ${ }^{23}$ For example, in the violent video game condition, the computer-operated avatars were programmed to attack the participants. However, these avatars behaved more peacefully in the nonviolent video game condition. Blood spots on the floor and the presence of guns in the game were also employed to insinuate a violent atmosphere. In addition, the participants assigned to the violent video game condition were allowed to use guns in the game. This ensured a more natural analog to commercial video games (see Figure 1).

The nonviolent condition lacked these hostile attributes (e.g., being attacked by enemy avatars). No guns were visible and the blood spots were replaced by splashed water (Figure 1). However, in both video game conditions the participants' avatars were given infinite health (i.e., invincibility). This allowed participants to withstand the attack of the computeroperated avatars, thus preventing excessive frustration because of dying in the violent video game condition. ${ }^{24}$ None of the participant-operated avatars perished while completing the experiment.

In addition, to minimize the differences in interactivity between the game environments, a number of elements were embedded in the nonviolent condition. For instance, the nonviolent game environment featured activities such as collecting health packs and activating switches. It is worth noting that controlling for interactivity and context differences has been particularly problematic when studying the effects of violent 
video games. For instance, Bartholow and Anderson ${ }^{25}$ used PGA Tournament Golf as a nonviolent gaming stimulus but employed Mortal Kombat as the violent gaming stimulus. A more recent study compared the effects of playing Doom, a first-person shooter, against the influence of playing the puzzle video game Mahjongg on aggressive self-perception. ${ }^{26}$ Also, to minimize the effects of cognitive load or whether different video games exert more or less mental effort on users, the study attempted to isolate statistically the effect gaming previous experience by using statistical techniques such as analysis of covariance (ANCOVA). Consider that, according to Bartlett et al., ${ }^{27}$ stimulating video games that require a certain amount of energy to complete are expected to increase cognitive performance but decrease cognitive load after repeated use. From this perspective, cognitive load is not a fixed property of video games but a subjective experience that correlates negatively with players' history of video game use (i.e., more gaming experience implies less cognitive load when playing video games). Although our attempts may not completely equalize the interactivity and cognitive load differences between both gaming conditions, the custom-made identical gaming environments and the use of ANCOVA are a significant improvements over the confounds in past studies (i.e., playing golf or Mahjongg are very different from a gory fight to the death, while the effects of cognitive load have received little attention).

The two gaming environments featured the same four poster-type advertisements. The posters featured selected brand logos (Figure 1). Real brands such as Nintendo, EA, Sega, and Konami were considered because game publishers usually embed in real brands in commercial video games. Congruent with this, related studies have also employed real instead of fictitious brands in order to enhance the ecological validity of the results. ${ }^{8,10}$ The selected brands were part of the top 15 biggest video game publishers. ${ }^{28}$ The in-game ads were highly visible, and they were installed at choke points that all participants had to go through when navigating the environments. The experimenter made sure that all participants had the same amount of time and successfully navigated all of the rooms in the game environments. These procedures intended to guarantee maximum and consistent in-game advertising exposure.

\section{Design and procedure}

Upon arrival at the laboratory the participants provided informed consent and were then randomly assigned to one of two video game conditions (violent condition: 17 males and 17 females; nonviolent condition: 17 males and 17 females). All experiments were conducted on a laptop connected to a 17 -inch color monitor with a mouse and a keyboard. The participants used the keyboard and mouse to navigate the video game conditions. All participants were trained in how to control their avatar to avoid frustration with the technology.

The participants then navigated the virtual environments in first-person perspective. They were given unlimited time to do so, but, on average, it only took them 2 minutes to complete the navigation task. After this, the participants were surveyed with measures of brand recall and recognition, brand attitudes, and purchase intentions. Next, the participants were asked about their age, gender, video game experience (years of video game playing and video game playing frequency), and computer use experience (in years). After filling out all the questionnaires, the participants were fully debriefed by the experimenter.

\section{Dependent measures}

Advertising effectiveness has been generally operationalized in terms of brand memory (recall and recognition) and brand attitude. ${ }^{11}$ In addition to this, the present study also considered a measure of stated purchase intention toward the brands. ${ }^{29}$

Brand recall. This factor was assessed by asking participants to list all of the brands they saw in the virtual environment (i.e., Nintendo, EA, Sega, and Konami). Brand recall was, therefore, a dichotomous variable (i.e., recall or no recall). The highest recall score possible was four, while the minimum was zero. Mean brand recall was $1.49(S D=0.98)$.

Brand recognition. This factor was measured by asking participants to make a decision on whether they saw a given brand in the video game. Ten possible brand names were presented to the participants but only four had actually appeared in the video game. Therefore, the remaining six brand names were foils (e.g., Capcom). The highest recognition score possible was four, while the minimum was zero. This scoring procedure only considers correct answers and controls for reporting false positive brands. For example, selecting Capcom does not increase brand recognition scores because it was a foil. Mean brand recognition was 2.21 $(S D=1.03)$.

Brand attitude and purchase intention. In addition to brand recall and recognition effects, the participants were asked to indicate their attitude toward each of the four brands using four different 7-point semantic differential scales after navigating the virtual environments. The scales considered the principles of the theory of planned behavior (TPB). ${ }^{29}$ For example, the participants were asked to evaluate statements such as "For me, the brand EA is _. Possible responses included typical TPB endpoints such as harmful/ beneficial, pleasant/unpleasant, good/bad, and worthless / valuable. This scale was reliable $(\alpha=0.86)$. Participants' responses were averaged to create a brand attitude index for the subsequent analysis.

Purchase intention was measured with three items that also reflected TPB assumptions. ${ }^{29}$ For instance, participants were asked to state whether "I intend to purchase video game title from (EA/Nintendo/Sega/Konami) between now and the holiday season." The three questions were responded using 7-point Likert-type scales where $1=$ "extremely unlikely" and $7=$ "extremely likely"). This scale was also reliable $(\alpha=0.88)$. Participants' responses were averaged to create a purchase intention index for the ensuing analysis.

\section{Results \\ Manipulation check}

A manipulation check was conducted to clarify participants' perceptions of violence of the experimental conditions. The violent and the nonviolent game contexts were evaluated with two questions asking participants how violent the content 
and graphics were on a 7-point Likert-type scale ranging from $1=$ "little to no violence" to $7=$ "extremely violent." Reliability tests on the two perceived violence items resulted in a Cronbach's alpha of 0.84. Participants' scores were averaged to create a perceived violence index. As expected, participants' ratings of perceived violence were significantly higher in the violent video game condition $(M=4.58, S D=1.34)$ in comparison to the nonviolent video game condition $(M=2.33, S D=1.50), \quad F(1,66)=41.94, p<0.001, \eta^{2}=0.39$. Thus the participants thought that the violent video game condition was significantly more violent than the nonviolent video game condition, indicating that the experiment successfully manipulated the gaming environments' level of violence.

As an additional manipulation check, participants' hostile moods were measured after navigating the experimental conditions. The questionnaire consisted of 35 adjectives from the state hostility scale (SHS) ${ }^{30}$ Reliability for the SHS resulted in a Cronbach's alpha of 0.93 . The SHS scores sought to establish whether the violent video game condition instilled a more hostile mood on the participants. However, a one-way ANOVA revealed no significant differences in participants' hostile mood scores between the violent $(M=1.81, S D=0.60)$ and the nonviolent video game conditions $(M=1.63$, $S D=0.57), F(1,66)=1.57, p=$ ns. This implies that although the participants in the violent video game condition perceived the game as comparatively more aggressive, their hostile mood was not significantly higher in comparison to participants in the nonviolent video game condition. This suggests that the subsequent analyses of brand recall, recognition, attitude, and purchase intention are unconnected to participants' affective states.

\section{The effects of violent video games on in-game brand recall and brand recognition}

Did the violent video game hamper brand recall and recognition in comparison to the nonviolent game? The question was addressed with an analysis of covariance (ANCOVA). Participants' gaming experience was used as a covariate in order to isolate the effect of familiarity with video games and the influence of differences in cognitive load between experienced and inexperienced gamers. Gaming experience was measured by asking the participants "In recent months, how often do you play video games?" on a 7-point Likert-type scale where $1=$ "rarely" and $7=$ "often." Since the brands embedded in the experimental game conditions were real, more avid players might have been previously exposed to these brands, thus enhancing their brand recall and recognition. For example, participants who played more video games had more positive attitudes toward the EA brand, $r(68)=0.35, p=0.002$, thus justifying the use of gaming experience as a covariate. No other links between gaming experience and brand attitude were found. Also, experienced gamers might have more available cognitive resources to process in-game ads as they have already mastered other games. ${ }^{31}$ Therefore, the study attempted to control statistically for the possible influence of participants' preexisting game experience by using covariation in the results reported below. However, perhaps surprisingly, the results were similar when gaming experience was not used as a covariate in the analysis.
As predicted, brand recall was significantly influenced by the video game environments, $F(1,63)=16.04, p<0.001$, $\eta^{2}=0.20$. In particular, brand recall was significantly lower for participants that navigated the violent video game environment $(M=1.14, S D=0.98)$ in comparison to those that navigated the nonviolent environment $(M=1.90, S D=0.90)$. As expected, brand recognition scores were also significantly lower for participants in the violent video game condition $(M=1.92, S D=1.15)$ compared to those in the nonviolent video game condition, $(M=2.55, S D=0.81), F(1,63)=6.48$, $p<0.05, \eta^{2}=0.10$. In sum, participants in the violent video game condition evidenced impaired brand recall and brand recognition compared to those in the nonviolent video game condition, thus supporting the limited capacity model's assumptions of H1. These results are summarized in Figure 2.

\section{Effects of violent video game context on brand attitude and purchase intention}

Did the violent video game elicit more negative brand attitudes and lower purchase intentions compared to the nonviolent video game? An ANCOVA procedure treating participants' gaming experience as a covariate was used to address the question. As predicted, the video game environments affected participants' attitudes about the brands, $F(1,63)=5.31, p<0.05, \eta^{2}=0.08$. Brand attitudes toward ingame ads were significantly lower for participants that navigated the violent video game environment $(M=3.90$, $S D=1.01)$ in comparison to those who explored the nonviolent video game environment $(M=4.29, S D=0.70)$. However, there were no significant differences between the violent and the nonviolent context in terms of participants' purchase intention toward the in-game ads $(F<1)$. Overall, participants' attitudes toward in-game brands were significantly lower in the violent than in the nonviolent video game condition. The results partially supported H2, as participants' purchase intentions were not affected by the game environments. These findings are represented in Figure 2.

The main effect of gaming environment over brand attitudes was qualified by significant interaction effect between video game condition and participants' gender, $F(1,63)=$ 4.67, $p<0.05, \eta^{2}=0.07$. Breaking down the interaction

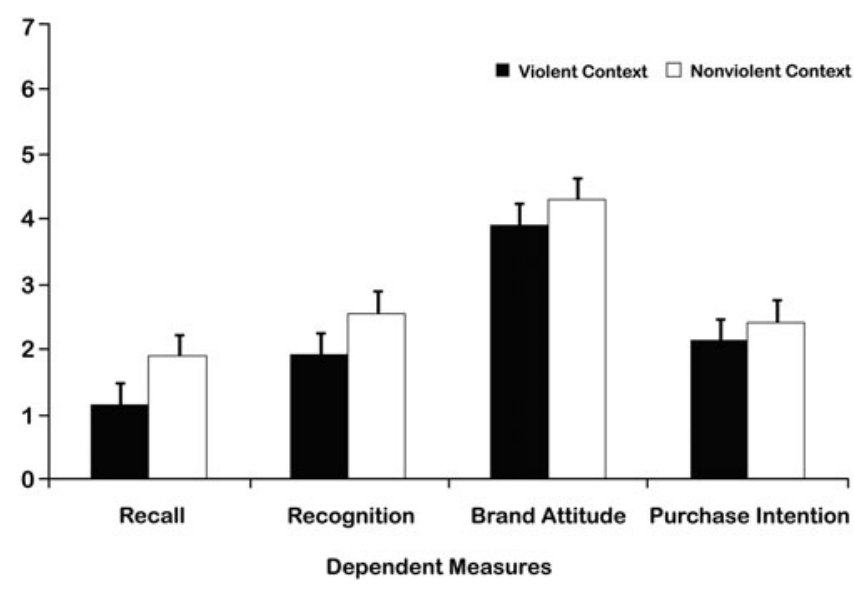

FIG. 2. Mean of brand recall, brand recognition, attitudes toward the brands, and purchase intention by each video game condition. 


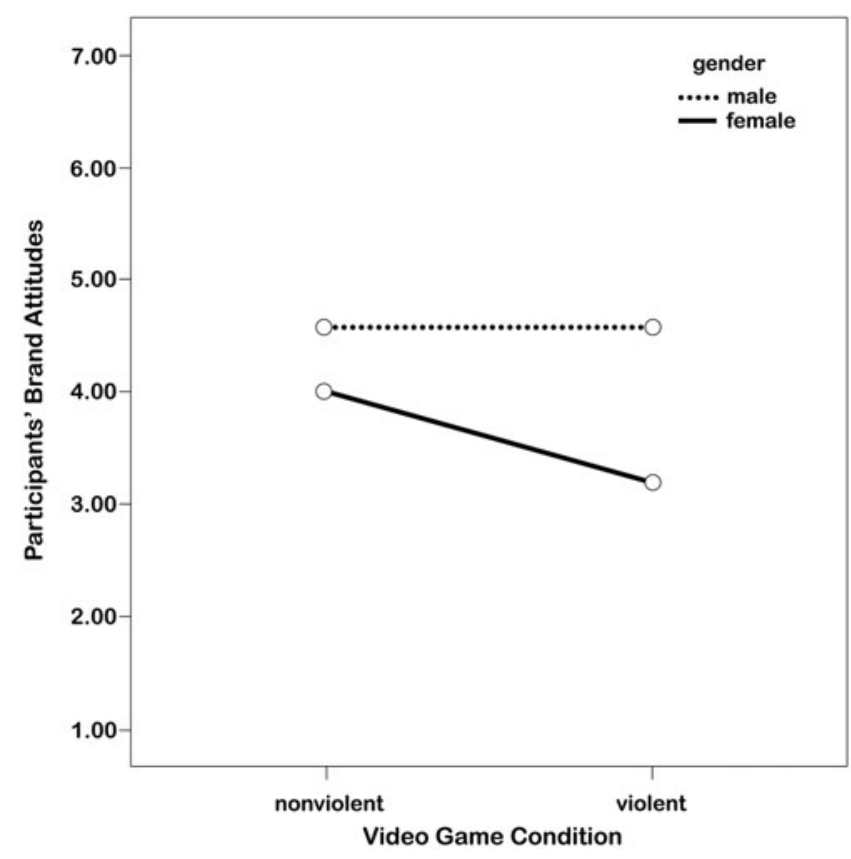

FIG. 3. Brand attitudes by video game condition and participants' gender.

revealed that female participants developed more negative brand attitude in the violent video game condition $(M=3.21$, $S D=0.77)$ in comparison to females in the nonviolent video game condition $(M=4.00, S D=0.62), t(32)=3.24, p<0.01$. These results appear in Figure 3. No other significant effects were found.

\section{Discussion}

The popularity of video games has captured the attention of advertisers hoping to increase exposure to their products. However, researchers have just begun to examine empirically the effectiveness of in-game advertising. Drawing from previous research, ${ }^{7}$ this study replicated the hypothesized ad impairment effect of media violence in the context of violent video games. Consider that previous studies investigating this hypothesis did not yield consistent results. ${ }^{10}$ Thus a main contribution of the present study is being one of the first to confirm the link between increased video game violence and impaired in-game ad effectiveness. In particular, participants' brand recall, brand recognition, and brand attitudes related to in-game ads were lower after navigating a violent video game in comparison to navigating an identical non-violent game (Figure 2). A second contribution of the present study is using identical video game scenarios. Consider that past studies have used games that are radically different (e.g., Mortal Kombat vs. 3D Pinball) to compare the cognitive effects of video game violence. Although our solution is not faultless, this methodological contribution improves upon the flaws of past gaming studies that used radically different games as independent variables. ${ }^{25,26}$

One explanation to the memory impairment effects of violent video games is provided by the limited capacity model of attention. ${ }^{14,15}$ From this perspective, violent video games draw more attention, but also divert awareness from other sources of information in comparison to nonviolent video games. ${ }^{7,10}$ All things being equal, our results suggest that users' mental capacity to process in-game ads is significantly more limited when playing a violent than a nonviolent video game. These findings thus extend seminal research on how televised violence diminishes advertising effectiveness. ${ }^{7}$ For example, the results suggest that violent video games can decrease advertising effectiveness in ways similar to violent television programs. ${ }^{7}$

In addition, the present study also suggests that video game environments can influence the perception of in-game ads. Participants that navigated a violent video game reported more negative evaluations of in-game ads compared to those who navigated a nonviolent video game. One interpretation of the negative effects of violent video games on the evaluation of in-game ads is cognitive priming theory. This perspective suggests that the evaluation of new information depends on related concepts that are salient in memory at the time that novel information is processed. Drawing from this perspective, the present study hypothesized and confirmed that a violent video game linked to negative attributes (e.g., blood, gore, death) has comparatively more negative effects on the evaluation of in-game brands.

These results add up to growing evidence of priming effects in games and virtual environments. ${ }^{32}$ For example, capitalizing on the association of wearing black uniforms and aggression, a recent study showed that participants using avatars in black uniforms subsequently reported more aggressive attitudes and intentions in comparison to those using avatars dressed in white uniforms. ${ }^{33}$ However, participants using avatars dressed in black reported less cohesion with their group than those using avatars dressed in white. These results suggest that situational cues in virtual environments can prime related attributes (e.g., aggressive attitudes) but inhibit inconsistent responses (e.g., group cohesion). Based on this, future studies should continue investigating how environmental cues in virtual environments (e.g., avatar and setting) can prime particular brand attitudes but, at the same time, inhibit inconsistent brand evaluations.

Recall that female participants' brand attitudes were significantly influenced by the game conditions compared to male participants. This finding might relate to gender differences in violent media consumption. For instance, female participants might have been less frequently exposed to violent media relative to male participants. In one study, while boys played video games for approximately 1.5 hours per day, girls only averaged about 40 minutes. ${ }^{34}$ Other studies suggest that girls are less inclined to play violent video games in comparison to boys. ${ }^{35}$ In the present study, gaming experience was indeed higher for males $(M=4.15, S D=1.82)$ compared to female participants $(M=2.65, S D=1.64), F(1$, 63) $=3.16, p<0.01, \eta^{2}=0.24$.

Overall, because mental models are constructed through experiences, females might be more inclined to disapprove of brands presented in a violent game because they lack exposure to video games in general and violent games in particular compared to males. It is also possible that males' previous experiences have desensitized them to the negative priming effect of violent games over the evaluation of ingame ads compared to females. ${ }^{25}$ Future studies should continue examining the interplay between priming mechanisms and gender when evaluating in-game ads. 


\section{Alternative explanations}

Although the present findings are congruent with the predictions of limited capacity and cognitive priming models, one alternative explanation to the memory impairment effect is that the violent video game condition augmented participants' negative affect. ${ }^{7}$ If so, participants' negative affect could be driving violent games' memory impairment effects instead of participants' cognitive processes. However, this explanation cannot fully account for the present results. Consider that the manipulation check showed that participants' hostile moods were not significantly affected by the video game conditions. Participants in the violent video game condition did not report increases in their hostile moods compared to those in the nonviolent condition. Therefore, there is no reliable evidence that participants' affect is connected to the memory impairment effects shown above. Nonetheless, future studies should continue examining the cognitive and affective foundations of violent video games' advertising impairment effects.

\section{Practical implications}

Practitioners might be interested in the paradox raised by the present results. Although violent video games are highly popular, their effectiveness as an advertising medium is questionable. While advertisers may increase product exposure when embedding ads in violent video games, this may come at the cost of lower brand recall and recognition, and more negative brand attitudes in relation to embedding ads in comparable nonviolent games.

One practical implication is that advertising budgets are perhaps best spent in ads embedded in nonviolent video games than in ads placed within violent video games. Users appear to have more cognitive resources at their disposal when playing nonviolent video games, and therefore they can spare more attention to in-game ads. Also, a nonviolent video game context may not taint the evaluation of in-game brands with attributes such as blood, death, and other concepts that may prime more negative in-game brand evaluations.

Along these lines, female participants in the violent video game condition reported significantly lower brand attitude scores than females in the nonviolent condition. It appears that in-game ads in violent video games might be particularly ineffective among females. This implies that advertisers should refrain from investing in ads in violent video games when targeting female gamers. Instead, advertisers should feature their brands and products in nonviolent video games when attempting to influence the brand attitudes of female gamers.

\section{Limitations}

Although the present findings have several implications for researchers and practitioners, some limitations should be addressed. First, the study employed real instead of fictitious brands. This is problematic because some video game brands are more popular than others (e.g., Nintendo is more popular than Sega). One recommendation is that future studies should attempt to replicate the present findings while using fictitious brands, although it is worth noting that most related studies have used real instead of fictitious brands..$^{8,10,36,37}$ We believe this limitation does not invalidate the results because participants in the violent and the nonviolent conditions were also given equal time and the in-game ads were placed at key choke points within the virtual environment. The experimenter also made sure that all of the participants successfully navigated the environments to ensure more or less equal ad exposure. Additionally, participants' gaming experience, which connects to previous knowledge of video game brands and to less cognitive load, was statistically controlled through a covariation. Therefore, the study guaranteed more or less equal in-game ad exposure within its shortcomings.

A second limitation is that participants' level of interaction with each game environment might have not been uniform. For example, participants assigned to the nonviolent game condition might have less to do in the game (i.e., navigating and collecting health packs) compared to those in the violent game condition (i.e., navigating and shooting), thus resulting in more available resources for advertising memory in the nonviolent condition. Including collectable interactive items such as health packs and switches in the non-violent condition lessened this limitation, although, admittedly, this may not fully equalize interactivity levels between the violent and the non-violent condition. However, this procedure is a significant improvement from previous studies that compared completely different types of video games. ${ }^{25,26}$ To alleviate the concern, future studies should attempt to replicate these results while controlling for differences in interactivity between violent and nonviolent games more effectively.

\section{Conclusion}

The present results suggest that advertising effectiveness in video games is affected by the game's level of violence. In particular, violent video games may diminish brand recall and recognition and prime more negative attitudes toward the brand. These effects are connected to basic mechanisms on how media features affect people's attention and exert subtle effects over the evaluation of subsequent stimuli. These findings have practical implications for those seeking to increase advertising effectiveness. Congruent with Bushman, ${ }^{7}$ advertising in violent media is not only morally questionable but also perhaps an ineffective advertising strategy.

\section{Disclosure Statement}

No competing financial interests exist.

\section{References}

1. Schmitt BH. Contextual priming of visual information in advertisements. Psychology \& Marketing 1994; 11:1-14.

2. Bushman BJ, Phillips CM. If the television program bleeds, memory for the advertisement recedes. Current Directions in Psychological Science 2001; 10:43-7.

3. Chaney IM, Lin KH, Chaney J. The effect of billboards within the gaming environment. Journal of Interactive Advertising 2004; 5:54-69.

4. Lenhart A, Jones S. Adults and video games. www.pew internet.org/ /media / /Files / Reports /2008/PIP_Adult_ gaming_memo.pdf (accessed Dec. 10, 2008).

5. Williams D. Virtual cultivation: Online worlds, offline perceptions. Journal of Communication 2006; 56:69-87.

6. Electronic Entertainment Design and Research. www.eedar .com/Uploads/Console $\% 20$ Intelligence $\% 20$ Briefing $\% 202007 \%$ 20Summary.pdf (accessed Oct. 20, 2007). 
7. Bushman BJ. Effects of television violence on memory for commercial messages. Journal of Experimental Psychology Applied 1998; 4:291-307.

8. Bushman BJ, Bonacci AM. Violence and sex impair memory for television ads. Journal of Applied Psychology 2002; 87:557-64.

9. Nelson MR, Keum H, Yaros RA. Advertainment or adcreep? Game players' attitudes toward advertising and product placements in computer games. Journal of Interactive Advertising 2004; 5:3-30.

10. Melzer A, Bushman BJ, Hofmann UG. (2008) When items become victims: Brand memory in violent and nonviolent games. 7th International Conference on Entertainment Computing, Pittsburgh, PA.

11. Law S, Braun-LaTour K. (2004) Product placements: How to measure their impact. In Shrum LJ, ed. The psychology of entertainment media: Blurring the lines between entertainment and persuasion. Mahwah, NJ: Lawrence Erlbaum, pp. 63-78.

12. Gardner MP. Advertising effects on attributes recalled and criteria used for brand evaluations. Journal of Consumer Research 1983; 10:310-18.

13. Yi Y. The effects of contextual priming in print advertisements. Journal of Consumer Research 1990; 17:215-22.

14. Kahneman D. (1973) Attention and effort. Englewood Cliffs, NJ: Prentice-Hall.

15. Lang A. The limited capacity model of mediated message processing. Journal of Communication 2000; 50:46-70.

16. Lang A, Newhagen J, Reeves B. Negative video as structure: Emotion, attention, capacity, and memory. Journal of Broadcasting \& Electronic Media 1996; 40:460-77.

17. Berkowitz L. Some effects of thoughts on anti- and prosocial influences of media events: A cognitive-neoassociation analysis. Psychological Bulletin 1984; 95:410-27.

18. Tulving E, Schacter DL. Priming and human memory systems. Science 1990; 247:301-6.

19. Higgins ET, Rholes W, Jones A. Category accessibility and impression formation. Journal of Experimental Social Psychology 1977; 13:141-54.

20. Shen F, Chen Q. Contextual priming and applicability. Journal of Advertising 2007; 36:69-80.

21. Bushman BJ, Anderson CA. Violent video games and hostile expectations: A test of the general aggression model. Personality \& Social Psychology Bulletin 2002; 28: 1679-86.

22. Smith SL, Wilson BJ, Kunkel D, et al. (1998) National television violence study. Newbury Park: Sage.

23. Farrar KM, Krcmar M, Nowak KL. Contextual features of violent video games, mental models, and aggression. Journal of Communication 2006; 56:387-405.

24. Eastin MS. Video game violence and the female game player: Self-and opponent gender effects on presence and aggressive thoughts. Human Communication Research 2006; 32:351-72.
25. Bartholow BD, Anderson CA. Effects of violent video games on aggressive behavior: Potential sex differences. Journal of Experimental Social Psychology 2002; 38:283-90.

26. Uhlmann E, Swanson J. Exposure to violent video games increases automatic aggressiveness. Journal of Adolescence 2004; 27:41-52.

27. Barlett CP, Vowels CL, Shanteau J, et al. The effect of violent and non-violent computer games on cognitive performance. Computers in Human Behavior 2009; 25:96-102.

28. Gamedeveloper: The top 20 video game publishers www.gamedevresearch.com/top-20-publishers-2008.htm (accessed Oct. 15, 2008).

29. Ajzen I. Constructing a TpB questionnaire: Conceptual and methodological considerations. www.unix.oit.umass.edu/ aizen/tpb.htm (accessed Apr. 20, 2005).

30. Anderson CA, Deuser WE, DeNeve KM. Hot temperatures, hostile affect, hostile cognition, and arousal: Tests of a general model of affective aggression. Personality \& Social Psychology Bulletin 1995; 21:434-448.

31. Lee M, Faber RJ. Effects of product placement in on-line games on brand memory: A perspective of the limited-capacity model of attention. Journal of Advertising 2007; 36:75-90.

32. Ivory JD, Kalyanaraman S. The effects of technological advancement and violent content in video games on players' feelings of presence, involvement, physiological arousal, and aggression. Journal of Communication 2007; 57:532-55.

33. Peña J, Hancock JT, Merola NA. The priming effects of avatars in virtual settings. Communication Research 2009; 6:838-56.

34. Roberts DF, Foehr UG, Rideout V. Generation M. Media in the lives of 8-18 year olds. www.kff.org/entmedia/upload/ Generation-M-Media-in-the-Lives-of-8-18-Year-olds-Report .pdf (accessed Nov. 11, 2006).

35. Buchman DD, Funk JB. Video and computer games in the '90s: Children's time commitment and game preference. Children Today 1996; 24:12-31.

36. Bushman BJ. Violence and sex in television programs do not sell products in advertisements. Psychological Science 2005; 16:702-8.

37. Yang M, Roskos-Ewoldsen DR. The effectiveness of brand placement in the movies: Level of placements, explicit and implicit memory, and brand choice behavior. Journal of Communication 2007; 57:469-89.

Address correspondence to: Seung-Chul Yoo

The University of Texas at Austin Department of Advertising

1 University Station Stop A1200

Austin, TX 78712, CMA 7142

E-mail: btl@mail.utexas.edu 